\title{
Bir Hidroelektrik Santralin (HES) Elektrik Şebekesindeki Harmonik Oluşumuna Etkisinin Incelenmesi
}

\author{
Mustafa TEKİN ${ }^{1}$, Ö. Fatih KEÇECIOĞLU ${ }^{1}$, Ömer ERAFŞAR², Mustafa ŞEKKELí ${ }^{*}$ \\ ${ }^{1}$ Kahramanmaraş Sütçü İmam Üniversitesi, Mühendislik - Mimarlık Fakültesi, Elektrik-Elektronik Mühendisliği \\ Bölümü, Kahramanmaraş, Türkiye \\ ${ }^{2}$ TEİAŞ Kahramanmaraş İşletme ve Bakım Müdürlügü Kılavuzlu Trafo Merkezi
}

\begin{abstract}
ÖZET: Elektrik enerjisi insan hayatının vazgeçilmez bir parçası olduğundan elektrik enerjisinin istenilen kalite ve standartlarda olması önem arz etmektedir. Gelişen teknolojiyle birlikte güç elektroniği esaslı elemanların ve nonlineer yüklerin kullanımı arttı̆̆ından elektrik enerjisinde kalite problemleri baş göstermiştir. Bundan dolayı elektrik enerjisini istenilen kaliteye getirmek için güç kalite parametreleri tanımlanmış ve bu parametrelerin standartları oluşturulmuştur. Bu parametrelerin en önemlilerinden biri harmoniklerdir. Bu çalışmada; bir Hidroelektrik Santralin (HES) elektrik şebekesini harmonikler açısından nasıl etkilediği irdelenmiştir. Örnek santral olarak Kahramanmaraş’ta bulunan Torlar HES isimli küçük ölçekli $(<25 \mathrm{MW})$ bir santral seçilmiştir. Güç analizörü ile bu santralde bir ay boyunca 24 saatlik ölçümler yapılmıș ve ölçümlerden elde edilen elektriksel verilerle oluşturulan grafikler analiz edilerek gerekli çıkarımlar yapılmıştır.
\end{abstract}

Anahtar Kelimeler: Güç Kalitesi, Harmonik, HES.

\section{Investigation Of The Effect Of A Hydroelectric Power Plant (HPP) In Electricity Network From The Standpoint Of Harmonic Generation}

\begin{abstract}
Because electrical energy is an indispensable part of human life, the required quality and standards of electric is important. With evolving technology, there have been quality problems because of use of power electronicsbased components and non-linear loads. Thus, for bring to electrical energy desired quality, power quality parameters are defined and the standards of these parameters have been established. One of the most important of these parameters are harmonics. In this study; a Hydroelectric Power Plant (HPP) are discussed in terms of harmonics how it impacts electric grid. The Torlar HPP which is small hydroelectric power plant in Kahramanmaraş, was selected for measurements. The measurements were made in this plant by network analyzer for one month during the 24 hours and charts that created with electrical measurement data which was obtained from analyzer, were analyzed and the necessary conclusions were made.
\end{abstract}

Keywords: Power Quality, Harmonic, HPP.

\section{GíRİş}

"Güç kalitesi” terimi, bir elemanın kullanım amacına uygun olarak davranışından ve ömründen herhangi bir kayba uğramaksızın çalışması için gereken elektriksel sınırlamalar olarak açıklanabilir. Enerji (gü̧̈) kalitesi ve enerji kalitesini etkileyen etkenler son yıllarda önemli bir araştırma kaynağ olmuştur; çünkü güç kalitesini düzeltmek için gerekli önlemler alınmadan önce, bu tür bozulmaların kaynakları ve nedenlerinin bilinmesi önemlidir. En temel güç kalitesi sorunlarının başında gerilim/akım dalga şeklinin ideal sinüs biçiminden uzaklaşması olarak tanımlanabilir ve bu dalga şekli üzerinde de enerji sistemlerinin dinamikliğinden kaynaklanan istenmeyen gürültüler oluşabilir. Dalga şeklinin ideal sinüs biçiminden uzaklaşmasının temel sebebi dağııım sistemlerinde bulunan nonlineer yüklerin varlığıdır.[1] Bu nonlineer yükler şebekede harmonik ( $50 \mathrm{~Hz}$ dışındaki sinyaller) oluştururlar. Doğrultucular, eviriciler, kaynak makineleri, ark fırınları, gerilim regülatörleri, frekans çeviriciler, motor hız kontrol düzenleri, kesintisiz güç kaynakları vb. harmonik üreten kaynaklara örnek olarak verilebilir. Harmoniklerin neden olduğu problemlerin başlıcaları; güç kesicilerinin açıklanamayan nedenlerle açması, transformatör ve motorların aşırı 1sınması, enerji iletim hatlarında kayıpların artması, kablo ve kondansatör gibi dielektrik malzemelerde bozulma, verimin azalması, enerji hatlarının yakınından geçen haberleşme sistemlerinin olumsuz yönde etkilenmesi, elektrik makinelerinde gürültülü çalışma ve mekanik salınımlar, rezonans olayları, güç faktörünün değişmesi, kontrol devrelerinin, bilgisayarların ve koruma rölelerinin hatalı çalışması şeklinde siralanabilir.[2,3,4] 
Yukarıda anlatılan sebeplerden dolayı, güç kalitesi problemi hem elektrik güç sistemleri hem de ulusal ekonomi için bir tehdit oluşturmaktadır. Oluşan bu tehditleri tespit etmek ve gerekli önlemleri almak için hem AG hem de OG gerilim seviyesindeki güç kalitesi incelemeleri ve araştırmaları ile alakalı son yıllarda birçok makale yayınlanmıştır. Çoğu durumda güç kalite parametreleri gerilimle ilişkilendirilirken, harmonikler akımda da ön plana çıtığından bu çalışmada akımla alakalı ölçümler de yapılmıştır.[5] Yapılan bu çalışmayla; Kahramanmaraş il sınırlarında bulunan Torlar HES'e ait ölçümler bir güç analizörü vasıtasıyla yapılmıştır. Bu ölçümlerden elde edilen veriler 1şığında bu santralin ürettiği elektrik enerjisinin şebekeye harmonik açısından ne gibi etkilerinin olduğu değerlendirilmiştir.

\section{HIDROELEKTRIKK SANTRALLERIN (HES) YAPISI}

Hidro enerji, göllerde ve önüne set çekilmiş barajlarda "Potansiyel Enerji" olarak, nehir vb. akarsularda, akıntılı deniz boğazlarında ve gel-git olaylarının yaşandığı denizlerde "Kinetik Enerji" olarak karşımıza çıkar. Baraj seti arkasındaki rezervuarda depolanmış durumda bulunan su, burada durgun vaziyette iken yükseklikle doğru orantılı olarak bir potansiyel enerjiye sahiptir. Söz konusu su kütlesinin, cebri borular veya tüneller vasitasıyla türbin çarkına doğru hareket ettirilmesi sonucu hareket halindeki su kütlesi, hareket hızının büyüklüğü oranında bir kinetik enerjiye sahip olacaktır. Küçük ölçekli bir hidroelektrik santralin yapısı Şekil-1'de görülmektedir.[6]

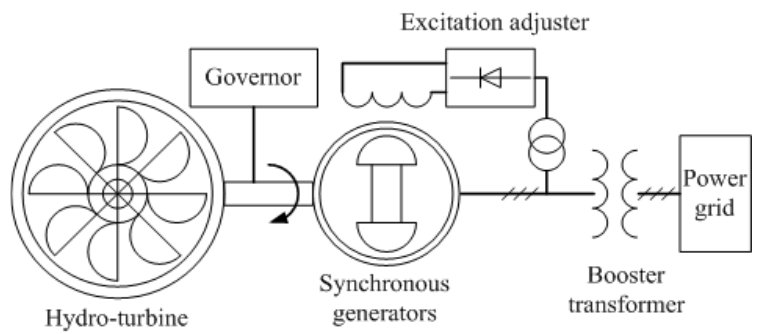

Şekil 1. Küçük Ölçekli Hidroelektrik Santralin Genel Yapis1[12]

HES'in çalışma prensibi kısaca aşağıdaki gibi özetlenmiştir:

Baraj gölünde biriktirilen su cebri boru vasıtasıyla türbin çarklarına taşınır. Üretime başlarken suyu homojen bir şekilde rotor etrafina dağılmasını sağlayan kelebek vanalar üretilecek enerjinin gücüne göre açılarak generatörün aktif hale gelmesi sağlar ve suyun hidrolik akım enerjisinden (Kinetik Enerji) elektrik enerjisi üretilir. Üretilen elektrik enerjisi güç trafoları vasıtasıyla gerilimi yükseltilerek enerji nakil hatları yardımı ile en yakım trafo merkezine gönderilir.
HES'ler kurulu güçlerine göre büyük ölçekli ve küçük ölçekli olarak sınıflandırılabilirler. Küçük ölçekli HES'ler için uluslararası bir sınırlama bulunmamakla birlikte üst sınır $2.5 \mathrm{MW}$ ile $25 \mathrm{MW}$ arasında değişmektedir. Dünya çapında kabul görmüş üst sınır $10 \mathrm{MW}$ olmasına karşılık Çin Halk Cumhuriyeti'nde bu sınır 25 MW olarak kabul edilmiştir. Genel olarak küçük ölçekli HES'lerde 2 MW'ın altındaki güçler mini, $500 \mathrm{~kW}$ 'ın altındaki güçler mikro-hidro ve $10 \mathrm{~kW}$ altındaki güçler ise pikohidro olarak sınıflandırılmaktadır. $\mathrm{Bu}$ sinıflandırma ülkelere göre farkl1lıklar göstermekle birlikte temel prensipler küçük ve büyük ölçekli HES'ler için aynıdır.[7] $\mathrm{Bu}$ çalışmada verilerin alındığı HES de küçük ölçekli bir santraldir.

\section{GÜÇ KALITTESİ YÖNETMELIKLERİ VE ÖLÇME STANDARTLARI}

Orta ve Alçak gerilim dağıtım şebekeleri için güç kalitesi limitlerinin belirlendiği en önemli standart, EN50160 olarak adlandırılan standart olup, pek çok ülkede çevirileri yapılarak kullanılmakta ve ulusal yönetmeliklere temel teşkil etmektedir.[5] Ülkemizde ise EN50160 standardı referans alınarak hazırlanmış "Elektrik Dağıtımı Ve Perakende Satışına İlişkin Hizmet Kalitesi Yönetmeliğii” kullanılmaktadır. Elektrik Dağıtımı Ve Perakende Satışına İlişkin Hizmet Kalitesi Yönetmeliğinde güç kalitesiyle alakalı bazı formül, tablo ve tanımlar aşağıda verilmiştir.

Fider: Bir merkez baradan müşteri veya müşteriler grubuna enerji taşıyan hat veya kablo çıkışlarıdır.

Harmonik: Doğrusal olmayan yükler veya gerilim dalga şekli ideal olmayan jeneratörlerden dolayı bozulmaya uğramış bir alternatif akım veya gerilimde, ana bileşen frekansının tam katları frekanslarda oluşan sinüzoidal bileşenlerin her biridir.

THB(Toplam Harmonik Bozulma): Gerilim veya akım harmonik bileşenlerinin etkin değerlerinin kareleri toplamının karekökünün, ana bileşenin etkin değerine oranı olan ve dalga şeklindeki bozulmayı yüzde olarak ifade eden ve aşağıdaki formüller uyarınca hesaplanan değerleri verir.[8]

$$
\begin{gathered}
T H B_{V}=\frac{1}{U_{1}} \sqrt{\sum_{n=2}^{\infty} U_{n}^{2}} \\
T H B_{I}=\frac{1}{I_{1}} \sqrt{\sum_{n=2}^{\infty} I_{n}^{2}}
\end{gathered}
$$


Söz konusu yönetmelikte; gerilim harmoniklerinin sınır değerleri Tablo-1 ve akım harmoniklerinin sınır değerleri Tablo-2'de verilmiştir.

Tablo 1. Gerilim Harmonikleri İçin Sınır Değerler[8]

\begin{tabular}{|c|c|c|c|}
\hline \multicolumn{4}{|c|}{ Tek Harmonikler } \\
\hline $\begin{array}{l}\text { 3'un Katlar } \\
\text { Olmayanlar }\end{array}$ & & $\begin{array}{l}\text { 3'un Katla } \\
\text { Olanlar }\end{array}$ & \\
\hline $\begin{array}{l}\text { Harmonik } \\
\text { Sirası } \\
\text { h }\end{array}$ & $\begin{array}{l}\text { Sinır } \\
\text { Değer } \\
(\%)\end{array}$ & $\begin{array}{l}\text { Harmonik } \\
\text { Sirası } \\
\text { H } \\
\end{array}$ & $\begin{array}{l}\text { Sinır } \\
\text { Değer } \\
(\%) \\
\end{array}$ \\
\hline 5 & $\% 6$ & 3 & $\% 5$ \\
\hline 7 & $\% 5$ & 9 & $\% 1,5$ \\
\hline 11 & $\% 3,5$ & 15 & $\% 0,5$ \\
\hline 13 & $\% 3$ & 21 & $\% 0,5$ \\
\hline
\end{tabular}

Tablo 2. Akım Harmonikleri İçin Sınır Değerler[8]

\begin{tabular}{|l|l|l|}
\hline \multicolumn{3}{|c|}{ Tek Harmonikler } \\
\hline $\mathrm{I}_{\mathrm{SC}} / \mathrm{I}_{\mathrm{L}}$ & $<11$ & $11 \leq \mathrm{h}<17$ \\
\hline$<20$ & 4.0 & 2.0 \\
$20<50$ & 7.0 & 3.5 \\
$50<100$ & 10.0 & 4.5 \\
$100<1000$ & 12.0 & 5.5 \\
$>1000$ & 15.0 & 7.0 \\
& & \\
\hline
\end{tabular}

\section{MATERYAL VE YÖNTEM}

\subsection{Harmonik Ölçümleri}

Ölçümler 01.05.2014 - 28.05.2014 tarihleri arasında TEİAŞ Kahramanmaraş İşletme ve Bakım Müdürlüğü Kilavuzlu Trafo Merkezinde, 33 kV Torlar HES Fider çıkışından alınmıştır. Torlar Hidroelektrik Santralinin Tek Hat Şeması (Ek-1) ekte verilmiştir. Torlar HES'in kurulu gücü 14836 kVA' dir. Santralin 2 adet 6,189 MW ve 1 adet 2,456 MW gücünde generatörü bulunmaktadır. Alınan bu verilerden 01.05.2014 tarihindeki bir günlük veriler değerlendirmeye alınmıştır. Ölçümler esnasında ION7550/ION7650 kodlu güç ve enerji ölçüm analizörü kullanılmıştır. Bu analizör birçok değeri ölçebilmesine rağmen bu çalışmada sadece harmonikler değerlendirmeye alınmıştır.

$\mathrm{Bu}$ makalede ele alınan güç kalitesi parametrelerinden ilki harmoniklerdir. Yapılan harmonik ölçümlerinde akım ve gerilim için Toplam Harmonik Bozunum (THB) grafikleri, üç faz akım ve gerilime ait bar grafikler, akım ve gerilime ait 3, 5 ile 7. harmoniğe ait akım ve gerilim değerleri verilmektedir. Diğer tekil harmonik değerleri çok düşük olduğundan grafik olarak verilmemiştir.

\subsubsection{Gerilime Ait Harmonik Ölçümler}

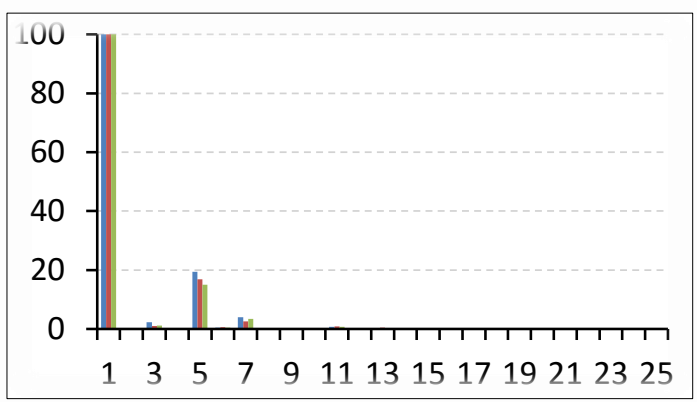

Şekil 2. 3 Faz Akıma Ait Harmonik Bozunumlar

Şekil 2'ye bakıldığında 3 faz gerilime ait yüzdelik olarak harmonik bozunumlar bar grafik olarak görülmektedir. Bar grafikler incelendiğinde; 5 ve 7 . harmoniğin baskın olduğu gözükmekte olup 3 ve 11 . harmoniklerin ise düşük değerlerde kaldığı anlaşılmaktadır. Her bir faza ait harmoniklerin yüzdelerinin de farklı olduğu şekil-2'de görülmektedir.

Şekil 3,4,5'te gerilime ait tekil harmonik $(3,5,7$. harmonikler) grafikleri verilmiştir. Şekil-3 incelendiğinde; 3 . harmonikte küçük dalgalanmalar olmasına rağmen bu harmoniğgin sınır değerler içinde olduğu anlaşılmaktadır.

Şekil 4 ele alındığında; 5. harmoniğin günün belli saatlerinde 5. harmonik için sınır değer olan \%6'lara kadar yükseldiği, günün diğer saatlerinde ise \%3-\%4 arasında değiştiği görülmektedir. 5. harmoniğin sınır değerlere yaklaşmasının sebebinin, o saatlerde santralin kademeli olarak devreden çıkmasının olduğu düşünülmektedir; çünkü türbinin fren sisteminde bulunan güç elektroniği esaslı elemanlar aktif hale gelmektedir.

Şekil 5'te verilen 7. harmoniğin ise sınır değerler içinde kaldığı gözlemlenmektedir. 7. Harmonik de 5. harmonikte olduğu gibi santralin devreden çıktığı saatlerde en yüksek değerlere ulaştığg anlaşılmaktadır.

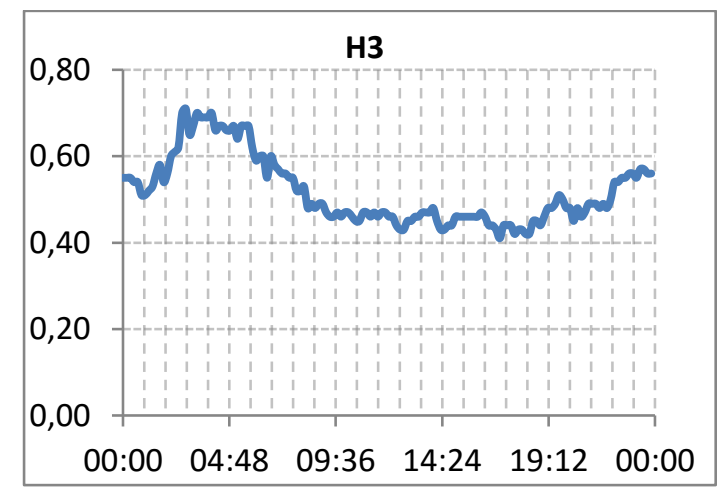

Şekil 3. Gerilime Ait 3. Harmonik 


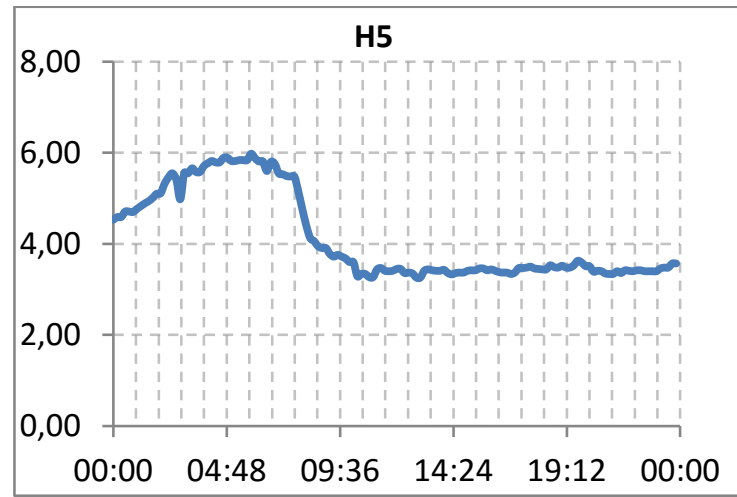

Şekil 4. Gerilime Ait 5. Harmonik

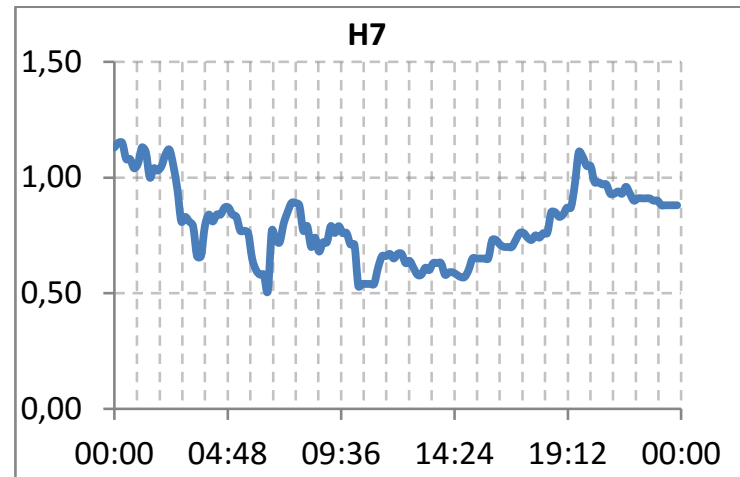

Şekil 5. Gerilime Ait 7. Harmonik

Şekil 6 ve şekil 7'de sırasıyla gerilime ait günlük ve haftalık THB değerleri görülmektedir. Şekil-6' ya bakıldığı zaman A fazına ait THB değerlerinin genel olarak eşik değerler içinde kaldığı ancak saat 02:00 ile 09:00 arasında sınır değeri (\%5) aştı̆̆ gözlemlenmektedir. Bunun sebebinin ise yine santralin kademeli olarak devreden çıkması esnasında kullanılan güç elektroniği esaslı anahtarlama elemanlarının olduğu düşünülmektedir.

Şekil 7'de gerilime ait bir haftalık THB değerleri verilmiştir. $\mathrm{Bu}$ değerlere bakıldığında bazı günlerde THB değerlerinin yüksek olmasına karşın sınır değeri aşmadığı görülmektedir.

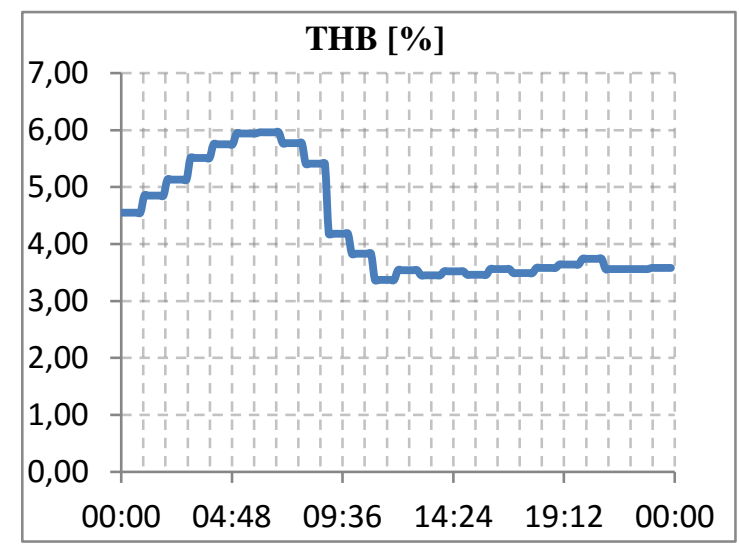

Şekil 6. Gerilime Ait THB Değeri

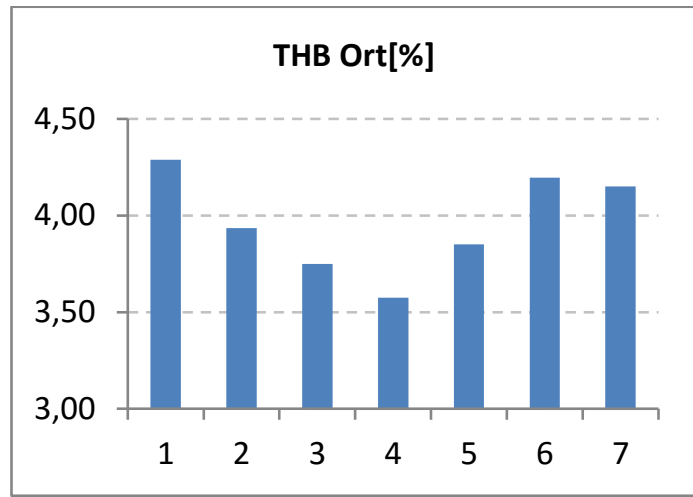

Şekil 7. Gerilime Ait Bir Haftalık THB’ler

\subsubsection{Akıma Ait Harmonik Ölçümler}

Şekil 8'e bakıldığında 3 faz akıma ait yüzdelik olarak harmonik bozunumlar bar grafik olarak görülmektedir. Bar grafikler incelendiğinde; 5. harmoniğin baskın olduğu gözükmekte olup diğer harmoniklerin ise çok düşük değerlerde kaldığı anlaşılmaktadır.

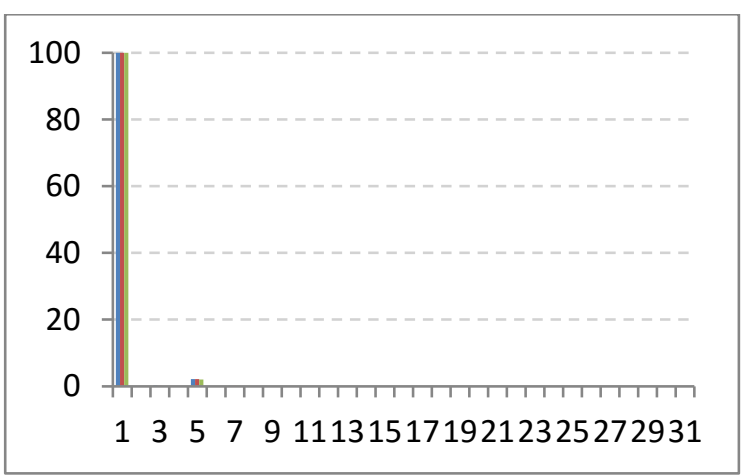

Şekil 8. 3 Faz Akıma Ait Harmonik Bozunumlar

Şekil 9,10,11'de akıma ait tekil harmonik (3, 5, 7. harmonik) grafikleri verilmiştir. Şekil-9'a bakıldığında; 3. harmonikte dalgalanmalar olmasına rağmen gerilimde olduğu gibi akım için de harmoniğin sınır değerler içinde olduğu anlaşılmaktadır. Aynı zamanda 3. harmoniğgin saat 03:00 ile 07:00 arasında santral devreden çıktığı için sıfır olduğu görülmektedir.

Şekil 10 incelendiğinde; 5. harmoniğin genel olarak $\% 2$ civarında seyrettiği fakat saat 03:20'de Maksimum değere çıkıp sınır değeri aştığı anlaşılmaktadır. Bu durumun nedeninin, santralden alınan analizör dataları incelendiğinde, saat 03:20 santralin tamamen devreden çıkmasının (güç elektroniği esaslı elemanlar devreye giriyor) olduğu düşünülmektedir. Saat 03:20 ile 07:00 arasında ise santral enerji üretmediği için 5. harmoniğin sıfır olduğu görülmektedir.

Şekil 11'de verilen 7. harmoniğin sınır değerler içinde kaldığ 1 ancak 5. harmonikte olduğu gibi saat 03:20'de (santralin tamamen üretimi sifirladı̆̆ zaman) maksimum değerini aldığ 1 (\%2) gözlemlenmektedir. 3 
ve 5. harmonikte olduğu gibi 7. harmoniğin de santralin üretim yapmadığı saatlerde $(03: 20$ - 07:00) sifir değerini aldığı görülmektedir.

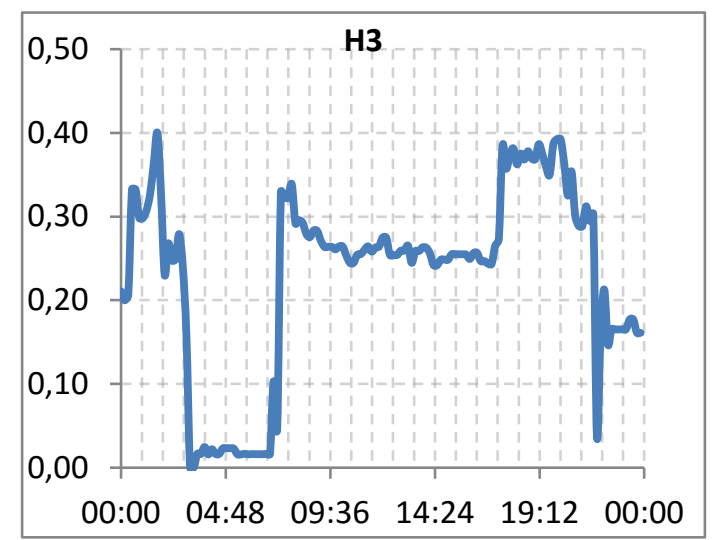

Şekil 9. Akıma Ait 3. Harmonik

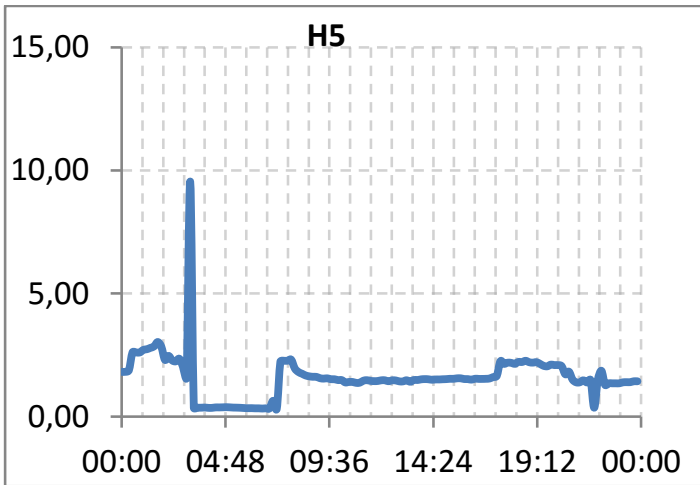

Şekil 10. Akıma Ait 5. Harmonik

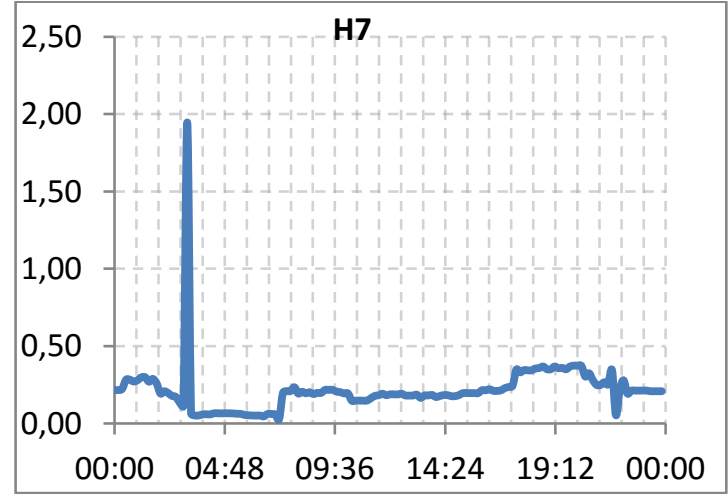

Şekil 11. Akıma Ait 7. Harmonik

Şekil 12 ve şekil 13'te sırasıyla akıma ait günlük ve haftalık THB değerleri görülmektedir. Şekil 12'ye bakıldığında A fazına ait THB değerlerinin maksimum $\% 3$ değerine ulaştığı fakat sınır değeri (\%5) aşmadı̆̆ görülmektedir. Gerilime ait THB değerinde olduğu gibi santralin üretim yapmadı̆̆ saatlerde akıma ait THB'nin sıfır olduğu anlaşılmaktadır.

Şekil 13'te Akıma ait bir haftalık THB değerleri verilmiştir. $\mathrm{Bu}$ değerler incelendiğinde her güne ait ortalama THB değerlerinin birbirinden farklı olmasına karşın eşik değere ulaşmadığından güç kalitesi açısından herhangi bir sorun teşkil etmediği anlaşılmaktadir.

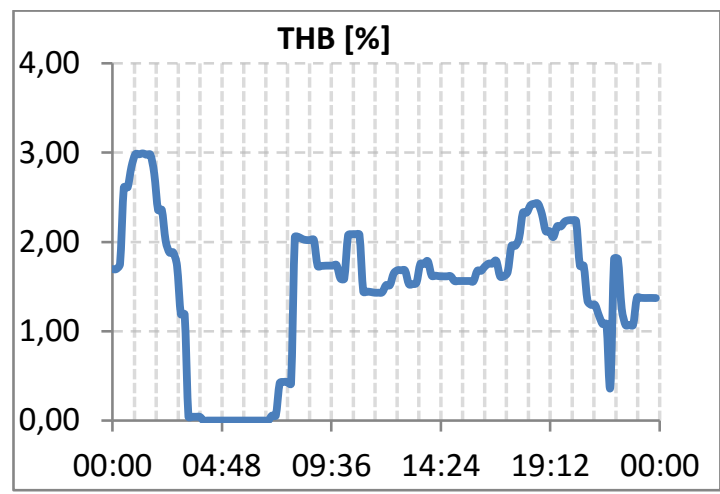

Şekil 12. Akıma Ait THB Değeri

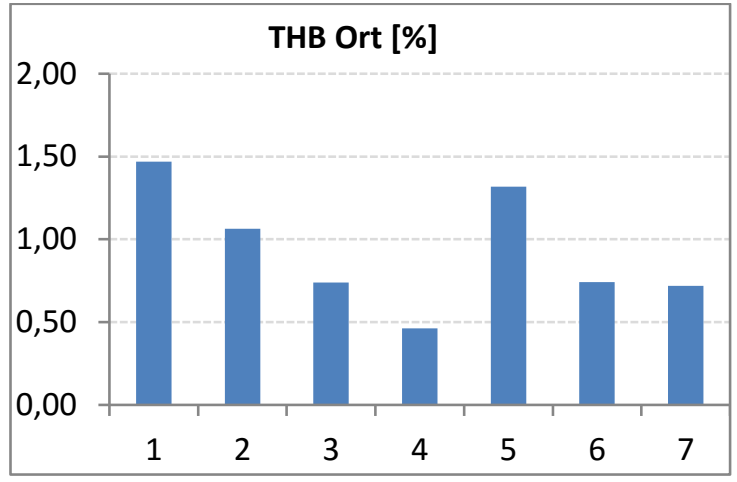

Şekil 13. Akıma Ait Bir Haftalık THB’ler

\section{SONUÇLAR}

Yapılan bu çalışmayla Kahramanmaraş ili, Merkez ilçesi sınırları içerisinde Körsulu Çayı üzerinde "Üretim Tesisi" olarak kurduğu 2 x $(6,375$ $\mathrm{MWm} / 6,189 \mathrm{MWe})+1 \times(2,544 \mathrm{MWm} / 2,456 \mathrm{MWe})$ lisans gücündeki Torlar HES'in Kilavuzlu Trafo Merkezine girdiği bağlantı noktasından 01.05.2014 28.05.2014 tarihleri her 10 dakikada bir ölçümler yapılmış ve ölçümler alınmıştır. Bu ölçümlerden elde edilen veriler vasıtası ile oluşturulan grafikler harmonik bozunum açısından incelenmiştir. Yapılan incelemeler sonucunda gerilimde 5 ve 7 . Harmoniklerin, akımda ise sadece 5. Harmoniğin baskın olduğu anlaşılmıştır. Gerilim harmoniklerinden sadece 5. Harmoniğin kısa bir süreliğine sınır değeri aştığ 1 görülmüştür. Akıma ait 5. Harmoniğin ise saat 03:20'de (santralin üretimi durdurduğu vakit) maksimum değere çıkarak kısa bir süre sınır değeri 
aştığı analiz edilmiştir. Gerilim ve akıma ait THB değerleri için elde edilen günlük ve haftalık grafikler incelenmiş olup THB'nin akım ve gerilim için sınır değerleri aşmadığ 1 ve güç kalitesi açısından problem oluşturmadığı anlaşılmıştır.

Sonuç olarak Bir Hidroelektrik Santralin güç kalitesi parametrelerinin en önemlilerinden biri olan harmonikler açısından şebekeye olumsuz etkisinin çok az olduğu görülmüştür.

\section{TEŞEKKÜR}

$\mathrm{Bu}$ çalışmanın yapılmasında anlayış ve yardımlarından ötürü Torlar HES yöneticilerine ve çalışanlarına teşekkürlerimizi sunarız.

\section{KAYNAKLAR}

[1]. Keçecioğlu, Ö.F., Tekin, M., Gani, A., Açıkgöz, H., Gemci, A., Şekkeli, M., "Bir Güneş Enerji Santralinin Elektrik Şebekesindeki Güç Kalitesi Parametrelerine Etkisinin İncelenmesi" KSÜ Mühendislik Bilimleri Dergisi 18(2), 2015.

[2]. Bayrak, M., Yeğin, E. M., Bilgin, M. Z., "Elektrik Güç Sistemlerinde Enerji Kalitesi." Türkiye 7: 3-8.

[3]. Tekin, M., Yılmaz, A.S., "Güç Sistem Harmoniklerinin Ayrık Hartley Dönüşümü İle İncelenmesi” V.Enerji Verimliliği Ve Kalitesi Sempozyumu Bildirileri, 2013.

[4]. Tunçalp, K., Kakilli, A., Sucu, M., "Bir Alçak Gerilim Elektrik Enerji Tesisinde Harmonik Ölçüm Sonuçlarının Matlab'de Simülasyonu Ve Pasif Filtre Uygulaması" Marmara Üniversitesi Teknik Eğitim Fakültesi Elektrik Eğitimi Bölümü-34722-İstanbul.

[5]. Keçecioğlu, Ö.F., Tekin, M., Gani, A., Sarı, M., Şekkeli, M., "Endüstriyel Isı Santrallerinde Enerji Kalitesi Ölçümü Ve Değerlendirilmesi, Kahramanmaraş Sütçü İmam Üniversitesi Örneği” 6. Enerji Verimliliği Ve Kalitesi Sempozyumu Bildirileri, 2015.

[6]. Şekkeli, M., Keçecioğlu, Ö.F., "Hidroelektrik Santrallerin Türkiye'deki Gelişimi Ve Kahramanmaraş Bölgesi Örnek Çalışması" KSÜ Mühendislik Bilimleri Dergisi 14(2), 2011.

[7]. Akpınar, A., Kömürcü, M.İ, Kankal, M., Filiz, M.H., “Çoruh Havzası'ndaki Küçük Hidroelektrik Santrallerin Durumu" V. Yenilenebilir Enerji Kaynakları Sempozyumu, Diyarbakır, 2009.

[8]. Elektrik Piyasasında Dağıtım Sisteminde Sunulan Elektrik Enerjisi Tedarik Sürekliliği, Ticari ve Teknik Kalitesi Hakkındaki Yönetmelik, Enerji Piyasası Düzenleme Kurumu (EPDK), 2016.
[9]. Domagk, M., Meyer, J., Schegner, P., "Seasonal Variations in Long-Term Measurements of Power Quality Parameters" PowerTech IEEE Eindhoven, Pages 1-6, 2015.

[10]. Barbulescu, C., Cornoiu, M., Kilyeni, S., Stoian, C., Stoian, P., "Electric Power Quality Issues: Harmonic Analysis for Real Network" EUROCON IEEE, 2013.

[11]. McBee, K.D., Simoes, M.G., "Evaluating the Long-Term Impact of a Continuously Increasing Harmonic Demand on Feeder-Level Voltage Distortion" IEEE Transactions On Industry Applications, Vol. 50, No. 3, May/June 2014.

[12]. YuanSheng, Z., XinRan, L., YuanYuan, X., JunYing, S., Hong, Y., "The Effects On The Load Model Of The Distributed Network With Small Hydro Power" The International Conference on Advanced Power System Automation and Protection, 2011.

[13]. Şekkeli, .M., Yılmaz, A.S., "Bir Taş Kırma Tesisinde Güç Kalitesi Seviyesinin Ölçümü ve Değerlendirilmesi” Pamukkale Üniversitesi Mühendislik Bilimleri Dergisi Cilt 15, Sayı 3, Sayfa 317-323, 2009.

[14]. Tekin, M., Yılmaz, A.S., “Güç Sistem Harmoniklerinin Ayrık Hartley Dönüşümü İle Analizi” KSU Mühendislik Bilimleri Dergisi, 18(1), 2015.

[15]. Akdeniz, E., "Yenilenebilir Kaynaklardan Enerji Üretiminin Şebekenin Enerji Kalitesi Ve Kararlılığına Etkilerinin İncelenmesi” Yüksek Lisans Tezi, 2006.

[16]. Yılmaz, M., "Elektrik Sistem Tasarımında Harmoniklern Giderilmesi İçin Bir Analiz" Yüksek Lisans Tezi, 2006.

[17]. Keçecioğlu, Ö.F., Tekin, M., Özalp, A., Şekkeli, M., Yılmaz, A.S., "Medikal Yoğunluklu Dağıtım Şebekelerinde Güç Kalitesi İncelemesi" V.Enerji Verimliliği Ve Kalitesi Sempozyumu Bildirileri, 2013.

[18]. Akbal, B., "Fabrika Beslemelerinde Harmonik Ölçümü Ve Filtre Tasarımı" Yüksek Lisans Tezi, 2011.

[19]. Erişti, H., Tümen, V., "K-means Kümeleme Yaklaşımı Kullanarak Elektrik Dağıtım Sistemlerindeki Harmoniklerin Zamansal Değişimlerinin İncelenmesi” ELECO Elektrik Elektronik ve Bilgisayar Mühendisliği Sempozyumu, 29 Kasım - 01 Aralık, Bursa 2012.

[20]. Yılmaz, A.S., Keçecioğlu, Ö.F., Tekin, M., Özalp, A., Şekkeli, M., “ Kent Merkezlerinde Güç Kalitesi İçin Saha Çalışması: Kahramanmaraş Örneği” APJES II-III 22-34, 2014.

[21]. Gencer, Ö.Ö., Yörükeren, N., Alboyac1, B., İnan, E., "Dağıtım Sistemlerinde Kullanılan Aydınlatma Aygıtlarındaki Harmoniğin Ölçümü, Yokedilmesi Ve Simule Edilmesiyle 
İlgili Yeni Bir Algoritma” II. Ulusal Aydınlatma Sempozyumu Ve Sergisi Bildirileri, 2003.

[22]. Mumyakmaz, B., Ünsal, A., Tunaboylu, N.S., "Elektrikli Demir yollarında Enerji Kalitesi Problemleri Ve Çözüm Önerileri” ELECO Elektrik - Elektronik ve Bilgisayar Mühendisliği Sempozyumu, 08-12 Aralık, Bursa, 2004.

[23]. Uyar, M., Yıldırım, S., Gençoğlu, M.T., “Güç Kalitesi Bozulmalarının Sinıflandırılmasında Dalgacık Dönüşümüyle Enerji Dağılımına Dayalı Özelliklerin İncelenmesi” ElektrikElektronik Bilgisayar Biyomedikal
Mühendisliği 12. Ulusal Kongre Ve Sergisi, 1418, 2007.

[24]. Kilıç, O., Acarkan, B., Ay, S., Gündüz, N., "Floresan Lambaların Harmonik Güç Hesapları Ve Ölçümü” V.Enerji Verimliliği Ve Kalitesi Sempozyumu Bildirileri, 2013.

[25]. Ertay, M.M., Alboyacı, B., Duru, H.T., Yeğin, E.M., "Endüstriyel Güç Sistemlerinde Oluşan Harmoniklerin Pasif Filtrelerle Yok Edilmesi" IV. Enerji Verimliliği ve Kalitesi Sempozyumu; Kocaeli, Türkiye, 58-63, 2011. 


\section{Ek: Tek Hat Şeması}

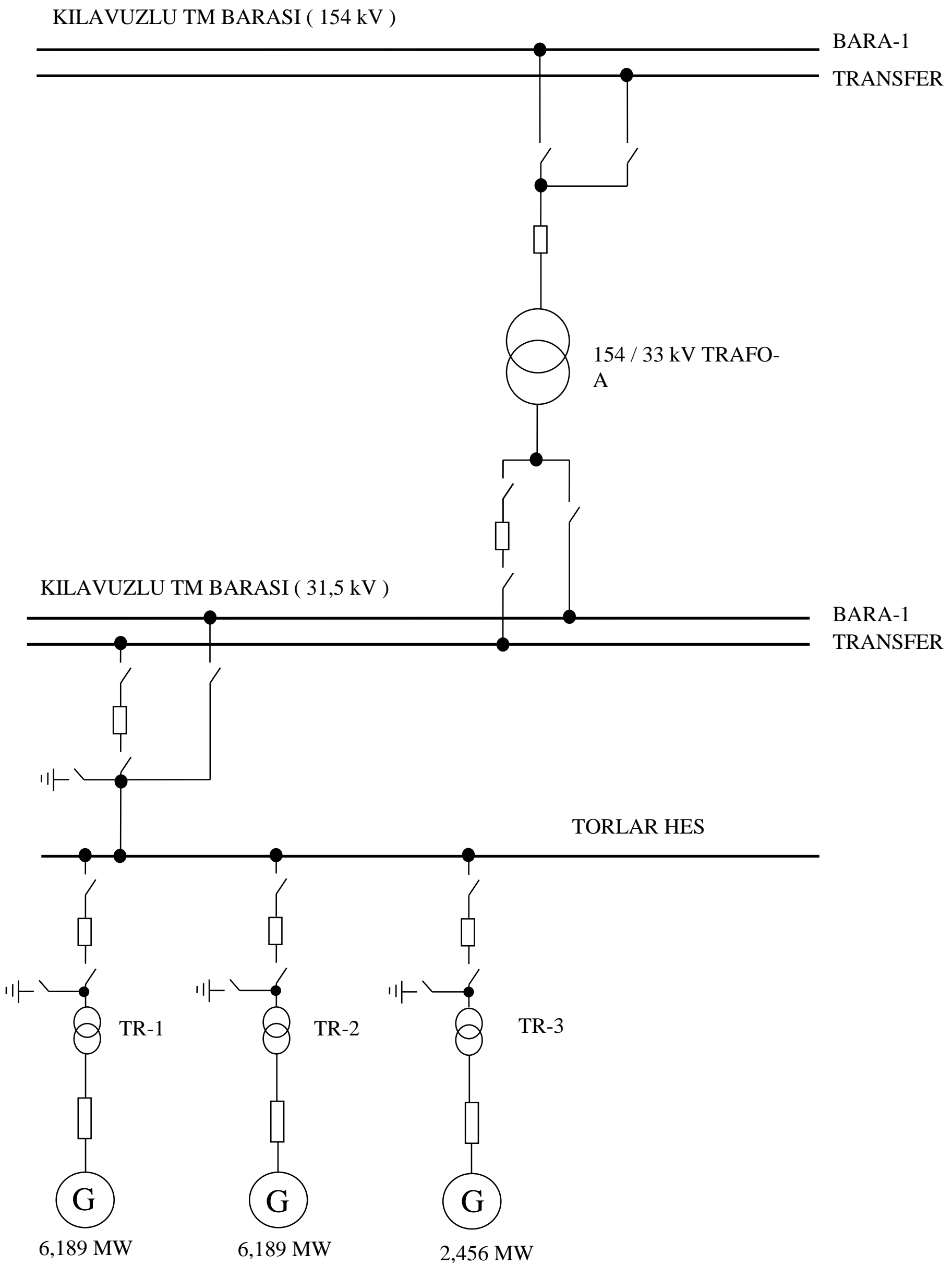

